\title{
Development and Testing of a Novel Cylindrical Permanent Magnet Linear Generator
}

\author{
M. A. H. Raihan, N. J. Baker, K. J. Smith, A. A. Almoraya, Student Member, IEEE
}

\section{AS ACCEPTED FOR PUBLICATION IN IEEE TRANSACTIONS ON INDUSTRIAL APPLICATIONS $>$ Newcastle university e print verion}

${ }^{1}$ Abstract - Vernier Hybrid Machines (VHMs) are known for their simple salient translator structure and inherent magnetic gearing, making them a strong candidate for low speed, high force applications. As both the armature coils and the permanent magnets are mounted on the stator, linear versions of this machine are attractive for applications with a large stroke amplitude. In most configurations, single sided or double sided flat cross sections are utilised, giving a two-dimensional flux path. In this paper, a cylindrical variant of the double-sided flat configuration is presented, where the flux path is now three dimensional. Three-dimensional finite element analysis (FEA) is used to design, analyse and compare both flat and cylindrical topologies for a fixed Permanent Magnet (PM) mass and current density. Details and test results of a Soft Magnetic Composite (SMC) based laboratory prototype of the cylindrical VHM are given which demonstrate the concept and validate the simulation results.

Index Terms - magnetic gearing, permanent magnet, Linear vernier machine, cylindrical machine, 3D finite element analysis, soft magnetic composite.

\section{INTRODUCTION}

$\mathrm{T}$ o facilitate direct drive power take-off and eliminate intermediate mechanical systems, low-speed force dense linear electrical machines are required in ocean wave energy converters. For example, a device with a peak power of $2 \mathrm{MW}$ and a stroke amplitude of $3.5 \mathrm{~m}$, would require a generator force of $1 \mathrm{MN}$ [1]. Linear permanent magnet machines have been shown to be good candidates for this application $[1,2]$ and several linear machine topologies have been proposed. Many capitalise on small pitch permanent magnets such as the Transverse Flux Machine (TFM) [1], flux-switching [3], and the Vernier Hybrid Machine (VHM) [4]. These variable reluctance machines (VRMs) provide high power density and require smaller machines to react a given force compared to conventional PM synchronous machines. The transverse flux machine in particular can offer high shear stress and is regarded as one of the most force dense machines for low current density applications. However, it has limitations in terms of fabrication as the three-dimensional (3D) flux paths may lead to a complex mechanical structure [5], and also limitations in terms of overload capacity and high inductance. Perhaps even more importantly, the TFM and other variants where the magnets are located on the translator give a poor magnet utilisation in linear machines with a long stroke, resulting from the requirement for a constant active area over a linear cycle. This is often achieved by the translator being longer than the stator, resulting in an overhang of permanent magnets that do not contribute to the active force.

Investigation into linear machine topologies has shown that variants where magnets and coils are both located on the stator in general give a less efficient magnet usage within the active area. They may still prove favourable for long stroke machines with an over length translator [6]. Vernier Hybrid Machines (VHMs) have both the PMs and the coils mounted in the stator and have been developed for low-speed high torque directdrive applications, either in rotary [7-9] or linear versions [10, 11]. Initially, they were also called Flux Reversal Machines due to the nature of their electromagnetic flux production [12, 13]. VHMs are known to exhibit a high force density as their slotted translator introduces reluctance variation and the split teeth give a magnetic gearing effect $[4,9]$.

Cylindrical variants of linear PM machines have been shown to give a higher force-to-weight ratio than flat topologies in some scenarios [14, 15]. A cylindrical cross section is also believed to have the potential to be more suitable for integration into wave energy converters as there is no requirement for the translator to resist torsional forces. Dynamic sealing is also likely to be less challenging on a cylindrical translator.

In this paper, a cylindrical VHM with a 3-dimensional (3D) flux path has been developed from a flat double-sided E-core linear VHM topology. The two topologies are compared from a fixed magnet mass perspective, the results of which were first reported by the authors in $[16,17]$. A pole shifting method has been analysed to reduce the cogging and force ripple of the cylindrical model. 3D finite element analysis has been performed in order to compare the flat and the cylindrical versions. The cylindrical version demonstrated a significant reduction in the cogging force and higher force density for a fixed PM mass and MMF at a laboratory scale. The design, build and testing of the cylindrical laboratory prototype are presented to evaluate and validate the predicted machine performance. The main design parameters are shown in Table I.

TABLE I

MAIN MACHINE PARAMETERS

\begin{tabular}{c|c}
\hline Parameters & Values \\
\hline Stator teeth per phase & 2 \\
No. of phases & 3
\end{tabular}

M. A. H. Raihan and all authors are with the School of Engineering, Newcastle University, Newcastle Upon Tyne, NE1 7RU, U.K.

(e-mail: M.A.H.Raihan1@newcastle.ac.uk) 


\begin{tabular}{c|c} 
Pole pairs per stator tooth & 3 \\
Air-gap length $(\mathrm{mm})$ & 1 \\
Stator pole pair pitch $(\mathrm{mm})$ & 24 \\
Translator tooth pitch $(\mathrm{mm})$ & 24 \\
Rated current density $\left(\mathrm{A} / \mathrm{mm}^{2}\right)$ & 3.5 \\
Rated speed $(\mathrm{m} / \mathrm{s})$ & 1.2 \\
\hline
\end{tabular}

\section{THE LINEAR VERNIER HYBRID MACHINE}

\section{A. Operation Principle and Force Development}

A flat double-sided E-core linear VHM is shown in Fig. 1 (a), as presented previously in $[18,19]$. The translator is made of iron laminations and sits in the middle of the stators. Due to the small pole pitch and multiple poles per stator tooth, moving the translator a short distance results in the phase windings seeing a high rate of change of flux. This magnetic gearing effect generates a high no-load Electro-Motive Force (EMF) even at low speeds and small displacements. This non-contact method of magnetic gearing enables the machine to react a higher force density without a conventional mechanical gearbox. According to the magnetic gearing principle $[13,20]$, the relationship between the PM pole pairs $\left(P_{P M}\right)$, stator armature winding pole pairs $\left(P_{w}\right)$ and active translator salient poles $\left(P_{t}\right)$ of the linear VHM machine can be given by:

$$
\begin{gathered}
P_{w}=\left|P_{t} \pm P_{P M}\right| \\
G_{r}=\frac{P_{t}}{P_{w}}
\end{gathered}
$$

Where $G_{r}$ is the magnetic gear ratio. Equations (1) and (2) show that in the topologies investigated in this paper, the gear ratio is equal to 4 .

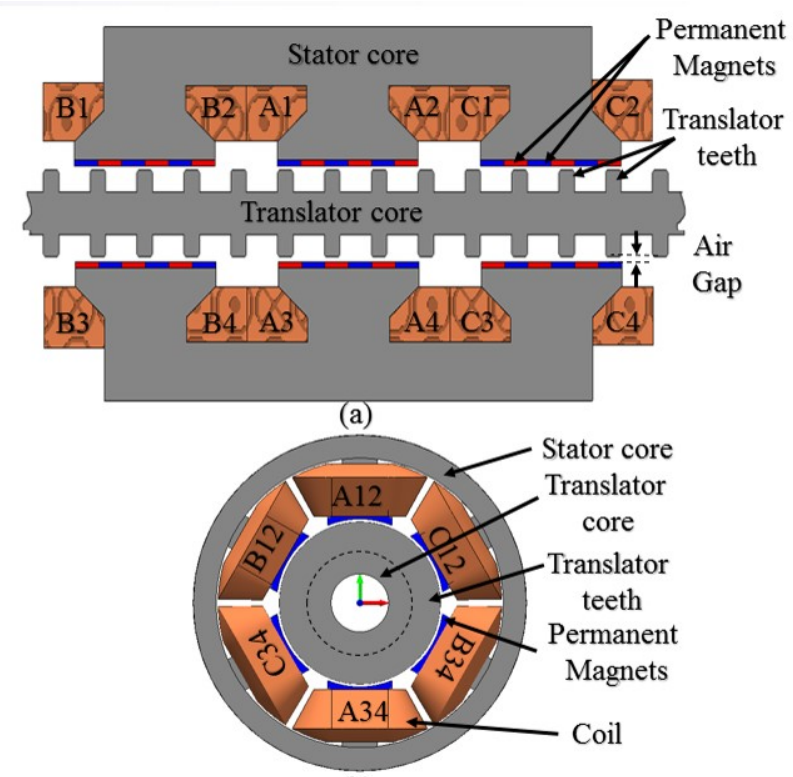

(b)

Fig. 1: (a) Flat double sided E-core Vernier machine (b) Novel cylindrical Vernier machine.

The thrust force is a function of armature current and the PM flux density. As the stator poles are not salient, the maximum thrust force is produced by applying the armature current in phase with the back EMF. This requires position sensing and a fully controlled, fully rated converter. However, associated control and power electronics will not be discussed in this paper.
Conceptually, the Magneto-motive Force (MMF) of the permanent magnets can be represented by an equivalent current $\left(I_{P M}\right)$ from an equivalent coil.

$$
I_{P M}=2 H_{c} L_{P M}=2 \frac{B_{r}}{\mu_{r} \mu_{0}} L_{P M}
$$

Where $H_{C}$ is the magnetic coercivity, $L_{P M}$ is the length of the magnets, $B_{r}$ is the remnant flux density of the PM, $\mu_{r}$ is the relative permeability of PM and $\mu_{0}$ is the permeability of free space. As mentioned in [21], by neglecting the higher order harmonics, the thrust force for each stator tooth can be derived from Lenz's law using (4).

$$
F=n i_{a} \frac{B_{0}}{B_{1}} \frac{t_{m}}{\left(t_{m}+g\right)} \frac{1}{\tau_{t}} B_{r} N \tau_{t} l_{a}
$$

Where $B_{0}$ is the average flux density, $B_{l}$ is the fundamental flux density, $n$ is the number of turns per coil, $i_{a}$ is the instantaneous current, $l_{a}$ is the axial or stack length of the machine, $t_{m}$ is the magnet thickness, $g$ is the air-gap length, $N$ is the number of translator teeth under each stator tooth and $\tau_{t}$ is the tooth pitch.

For the proposed linear vernier machine each phase consists of two stator teeth. Translator tooth width is defined as $t$ and thus the thrust force $\left(F_{x}\right)$ that acts in the direction of motion for the three-phase machine be expressed as a function of flux density at the tip of the tooth $\left(B_{t}\right)$ and can be derived from (3) and (4) to give (5).

$$
F_{x}=6 \frac{B_{t} B_{r}}{\mu_{r} \mu_{0}} \frac{B_{0}}{B_{1}} \frac{t_{m}}{\tau_{t}} N l_{a}
$$


(a)

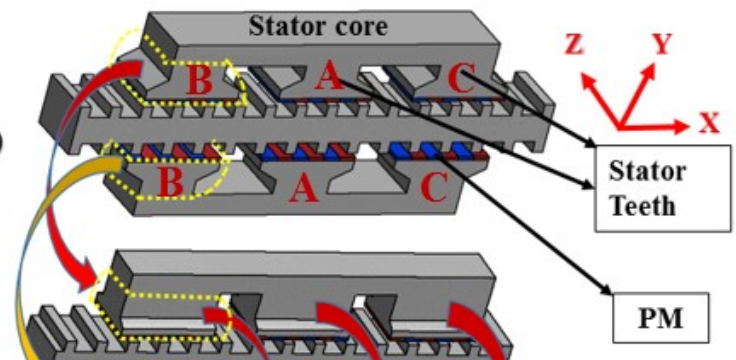

(c)

(b)

(d)

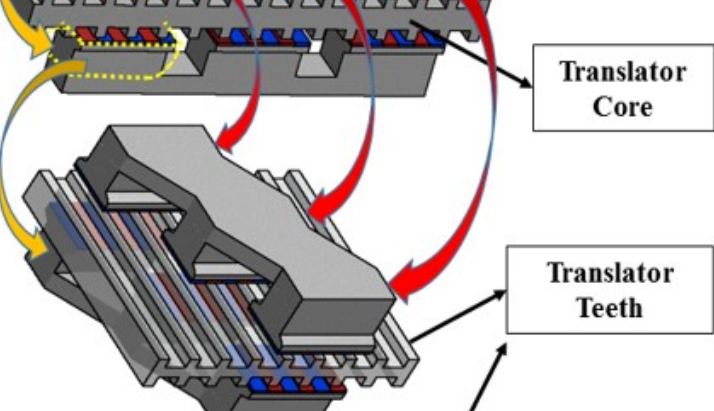

(e)

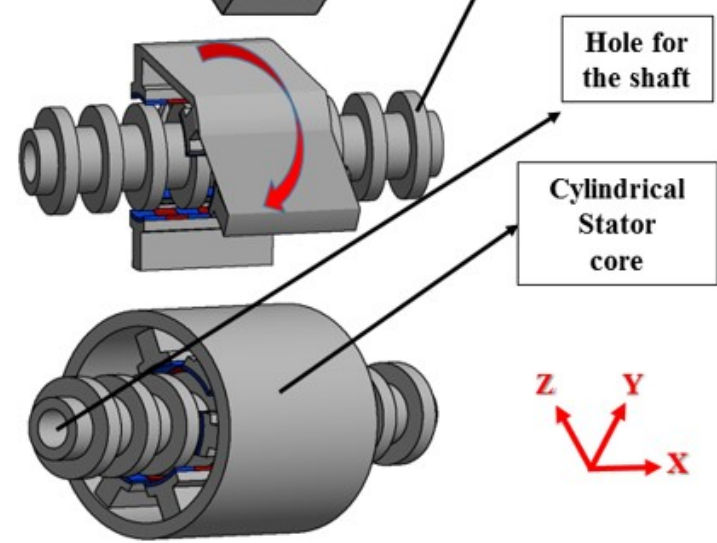

Fig. 2: Cylindrical Vernier machine topology development.

\section{Development of The New Cylindrical Topology}

Cylindrical linear machines have the merit of a smooth cross section offering a better surface for sealing than the flat (square) counterpart. The increased surface area to volume ratio makes for shorter stators. In addition, a reduction in the number of component parts compared to flat versions potentially makes cylindrical versions easier to manufacture and build. Finally, the axisymmetric structure of the cylindrical model enables the generator to withstand parasitic forces/torques equally well from all directions. Hence, a cylindrical version of the linear VHM is developed from the previously reported double-sided flat version [16] as shown in Fig. 2 by the following steps:

1. Rotating the stator teeth $90^{\circ}$ around the axis of PM's magnetization (Y-axis), shown in Fig. 2 (b).

2. Extending the translator teeth along the axial length ( $\mathrm{Z}$ axis).

3. Shifting the stator teeth pairs under phase A and phase $\mathrm{C}$ to be almost aligned with the teeth under phase B. For a 120 electrical degree phase shift between three phases, phase A, B and $\mathrm{C}$ must be offset relative to each other in the $\mathrm{X}$ direction, Fig. 2(c). If $\tau_{t}$ is the translator pitch, then the shift is defined as $X_{\text {shifitin (6). }}$.

$$
X_{\text {shift }}=\tau_{t}\left(n \pm \frac{1}{3}\right) ; n=0,1,2,3 \ldots
$$

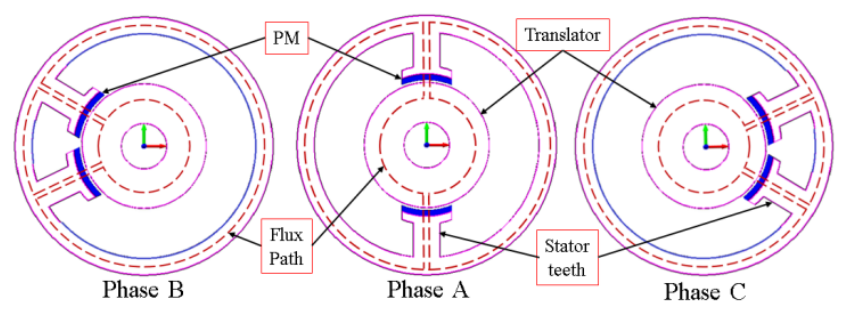

Fig. 3: 2D flux path representation of the separated three phases of the cylindrical machine

The two stators and the translator are now wrapped around the axis of motion (X-axis) to form a tubular structure -Fig. 2(d). Thus, magnets and stator teeth are formed into arc shapes. The stator cores now form a cylindrical shell covering all six stator teeth, shown in Fig. 2(e).

\section{A. Operation}

The principle of operation of the linear cylindrical Vernier Hybrid Machine is almost identical to the flat version, with the alignment and un-alignment of PM and translator teeth directing the magnetic flux around the stator and translator. In the flat machine, each phase interacts with adjacent sets of translator teeth. In the cylindrical model, however, all stator teeth sit on a combined core back and interact with the same set of translator teeth. The flux path can be visualized from Fig. 3, showing the three independent flux paths for three phases in the alignment position. In the miss-alignment position, most of the flux leaks due to the opposite polarities of the adjacent magnets and the resultant flux linkage in those coils under the same phase is almost zero.

In the flat machine, individual phases are adjacent and so the main flux flow in the core back is in the direction of motion. In the cylindrical machine, there is only a small axial shift between the stator teeth, defined as $X_{\text {shift }}$ in (6). The majority of all six stator teeth overlap the same part of the translator and hence the main flux flow is circumferential. There is just a small axial flux flow through the translator core at the end of the stator teeth to accommodate the nonoverlapping part of the stator, $X_{\text {shiff. }}$ The translator coreback can therefore be downsized for the cylindrical model compared to the flat version.

\section{MAChINE PeRformance AND Optimisation}

\section{A. Basic comparison}

Both the flat and the cylindrical VHM topologies have been built and investigated in FEA. For simplicity, the crosssectional areas of the stator teeth of both machines are shown to be equal in Fig. 4 [17]. The stator tooth of the cylindrical machine is seen to have a width of $l_{a} / 2$. Where $a$ is the PM width and $l_{a}$ is the axial length of the machine.

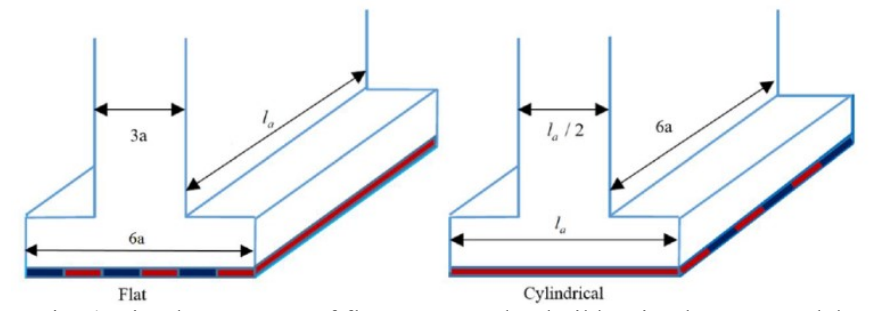

Fig. 4: Simple geometry of flat VHM used to build a simple mass model. 


\section{B. Local Optimisation}

Magnet thickness and translator tooth width of the cylindrical machine have been investigated to provide maximum average thrust force and back EMF. Similar results are obtained when analysing the flat machine and the fundamental pole dimensions are fixed between the two machines. This also ensures magnet mass is kept equal, which is the fundamental basis of comparison.

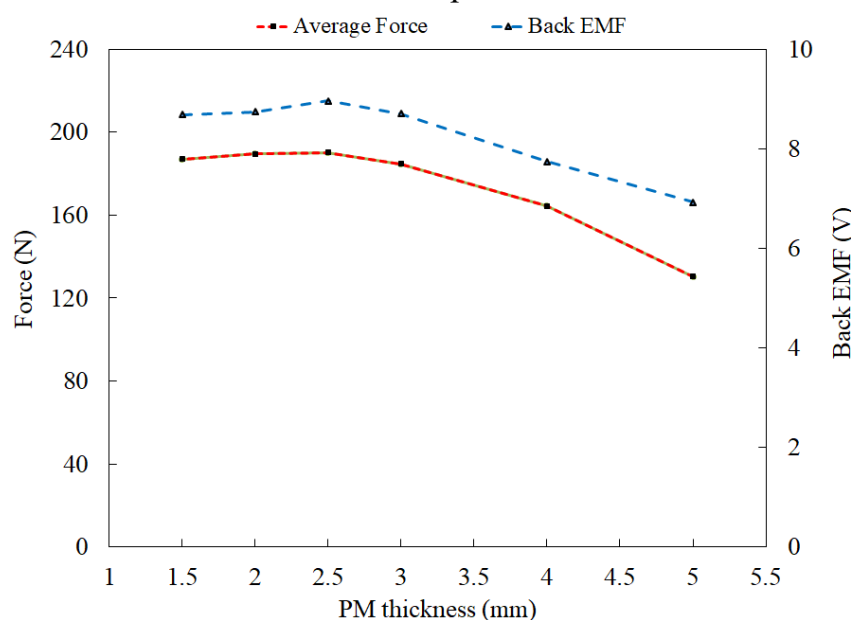

Fig. 5: Sensitivity analysis of translator tooth width of the cylindrical VHM

For a fixed PM width of $12 \mathrm{~mm}$, a $2.5 \mathrm{~mm}$ thickness of PM is proved to provide the highest back EMF and average thrust force (Fig. 5). Generally, the increase in PM thickness would be expected to cause average force and back EMF to increase linearly. However, in reality the ratio of leakage to active flux linkage becomes larger at higher magnet thicknesses. Consequently, back EMF and the average force starts to reduce. Similarly, air-gap flux density reduces for a PM thickness of less than $2.5 \mathrm{~mm}$, which causes back EMF and average force to reduce. Additionally, $2.5 \mathrm{~mm}$ is known to be a good physical lower limit on thickness, as thinner PMs are hard to handle as they are prone to breaking.

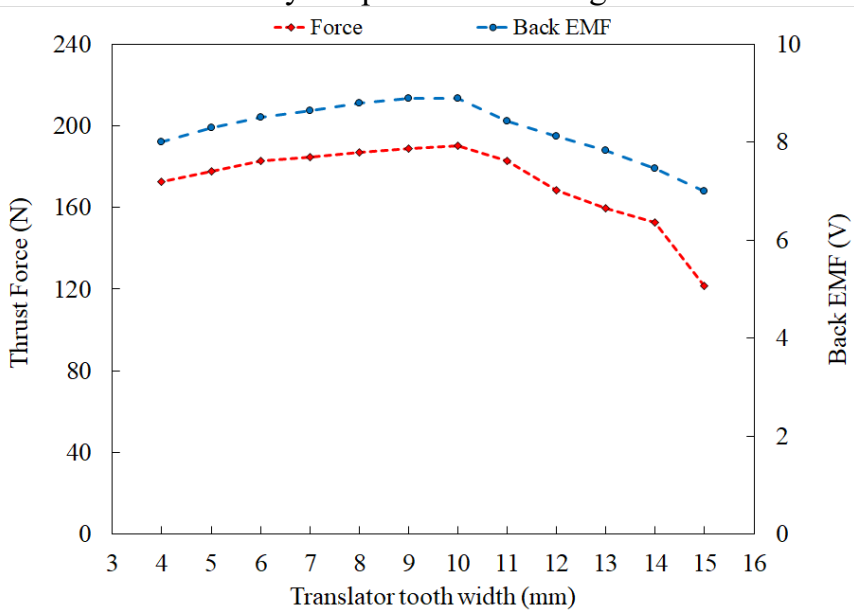

Fig. 6: Sensitivity analysis of translator tooth width of the cylindrical VHM

The effect of tooth width on back EMF and average force capability is investigated in Fig. 6, which shows that the 10 $\mathrm{mm}$ translator teeth provide the highest average force. Further reduction of the translator teeth causes saturation at rated current, reducing the average force. Therefore, a $10 \mathrm{~mm}$ translator tooth is selected.
The important parameters including PM mass, stator tooth width and stator yoke thickness are all fixed between both the topologies and presented in Table II.

TABLE II

MODEL PARAMETERS FOR BOTH MACHINE TOPOLOGIES

\begin{tabular}{c|c|c}
\hline Parameter & Flat & Cylindrical \\
\hline No. of coils per phase & 2 & 2 \\
No. of phases & 3 & 3 \\
PM thickness (mm) & 2.5 & 2.5 \\
PM length / arc (mm) & 22.5 & 22.5 \\
PM width (mm) & 12 & 12 \\
Stack length / outer diameter (mm) & 22.5 & 116 \\
PM mass (kg) & 0.18 & 0.18 \\
Stator teeth width (mm) & 36 & 12 \\
Stator yoke (mm) & 18 & 8 \\
Translator tooth width & 10 & 10 \\
\hline
\end{tabular}

C. Reduction of Cogging by Pole Shifting

In section II, (1) and (2) demonstrated the relationship between pole pair combinations and the magnetic gear ratio. There is an equivalent relationship between pole slot combinations, cogging force and force ripple. It is found that fractional gear ratios provide the best performance in terms of cogging and torque ripple for magnetic geared machines [22]. In this study, an integer gear ratio is used and so reduction techniques are required to mitigate the cogging and ripple forces. In [23], Zhu introduced the goodness factor, $C_{T}$ of slot pole combination of rotary PM synchronous machine in terms of cogging torque.

$$
C_{T}=\frac{p \cdot n}{l c m(p, n)}
$$

Where $p$ is the number of rotor poles and $n$ is the number of stator slots. Although there is no direct relationship between the goodness factor and amplitude of cogging torque, it is found that the lower $C_{T}$, the smaller the cogging. This implies that a high lowest common multiple between $p$ and $n$ is required. It is almost impossible to design a magnetic geared machine with a low radial force and low cogging torque without skewing [24]. The dominant $k^{\text {th }}$ order harmonics can be minimised by adopting a skewing angle, $\alpha$ between $m$ straight lamination stacks,

$$
\alpha=\frac{360^{\circ}}{m k}
$$




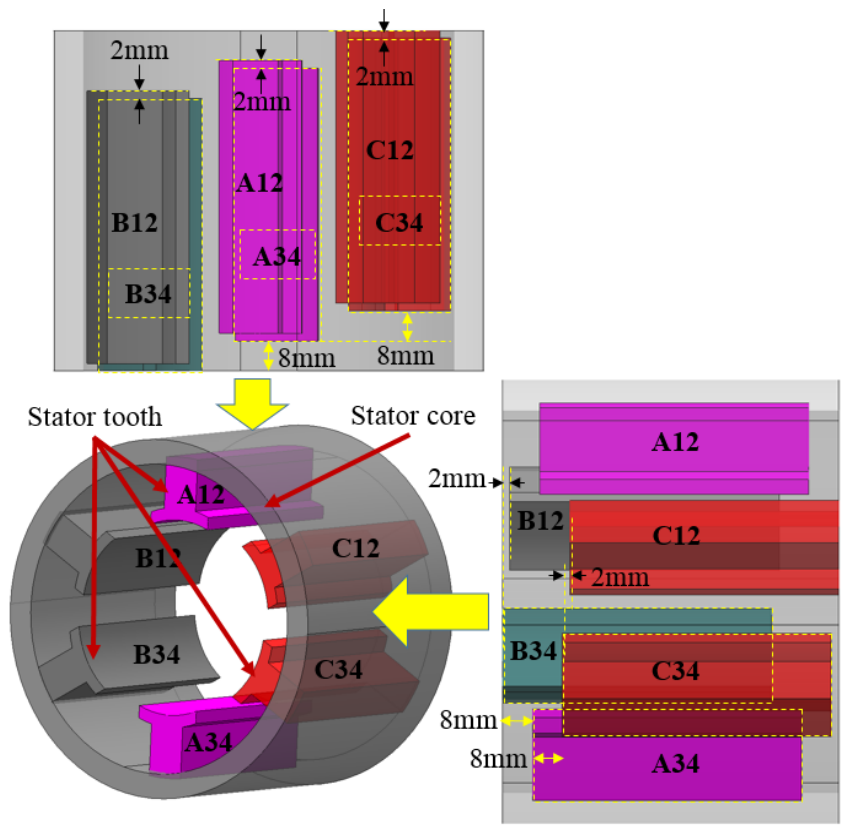

Fig. 7: Stator teeth geometry of the cylindrical VHM for cogging reduction.

Pole shifting is equivalent to skewing or short pitching in linear machines, which eliminates or minimises the parasitic effects of the higher order harmonics in the cogging force [25]. The cylindrical variant of the double-sided VHM topology is analysed to minimise the cogging and force ripple by implementing a pole shifting method.

Fig. 7 illustrates the stator teeth including pole shifting for the cylindrical topology. The six stator teeth are labelled as A12, A34, B12, B34, C12 and C34 under three phases - A, B and $\mathrm{C}$. Each phase is physically shifted in the direction of motion by $8 \mathrm{~mm}$ (one third of the translator tooth pitch) with respect to each other, which is equivalent to $120^{\circ}$ electrical. To illustrate pole shifting method, one tooth of each phase (A12, $\mathrm{B} 12$, and $\mathrm{C} 12$ ) remains in a fixed position, while the other teeth (A34, B34, and C34) are shifted. In Fig. 7, A34, B34, and C34 are shifted by $2 \mathrm{~mm}$ from A12, B12 and $\mathrm{C} 12$ respectively, which is equivalent to a $30^{\circ}$ electrical shift.

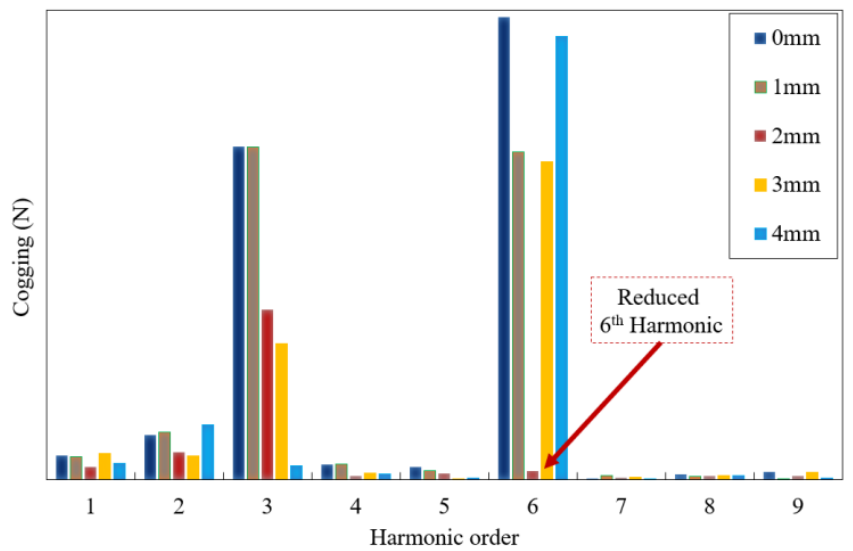

Fig. 8: Harmonic distribution for different pole shifted models.

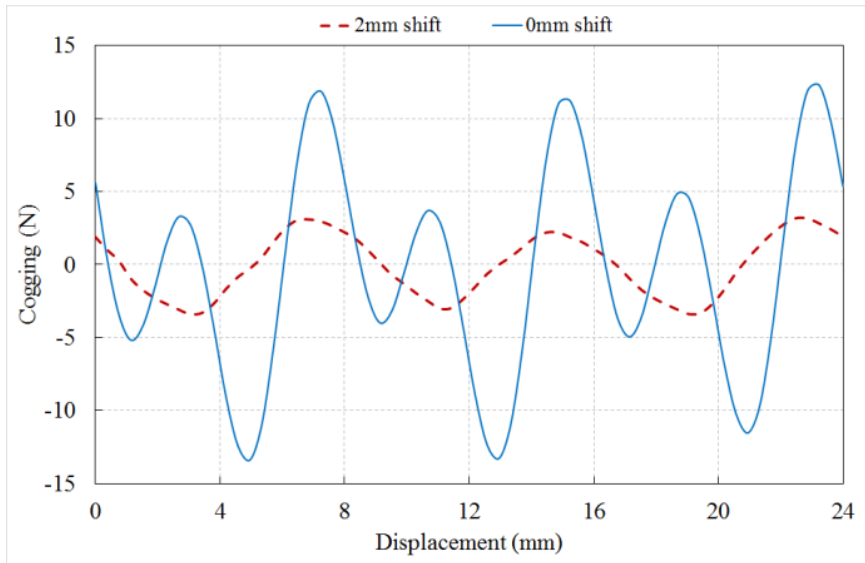

Fig. 9: Cogging force variation by implementing pole shifting

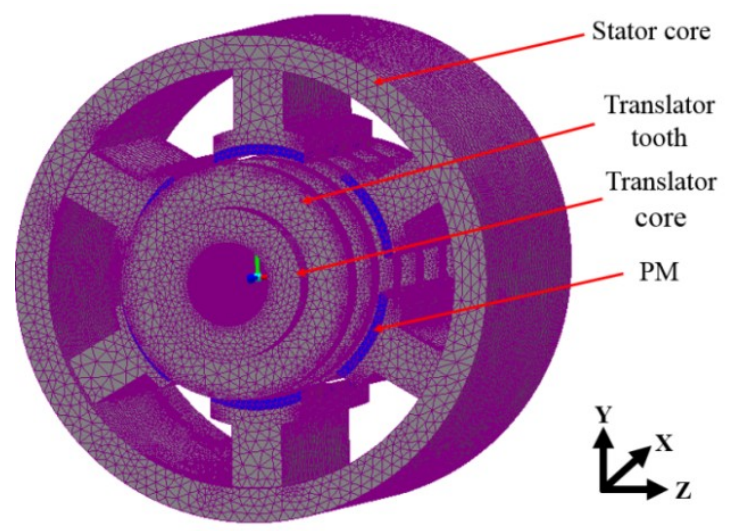

(a)

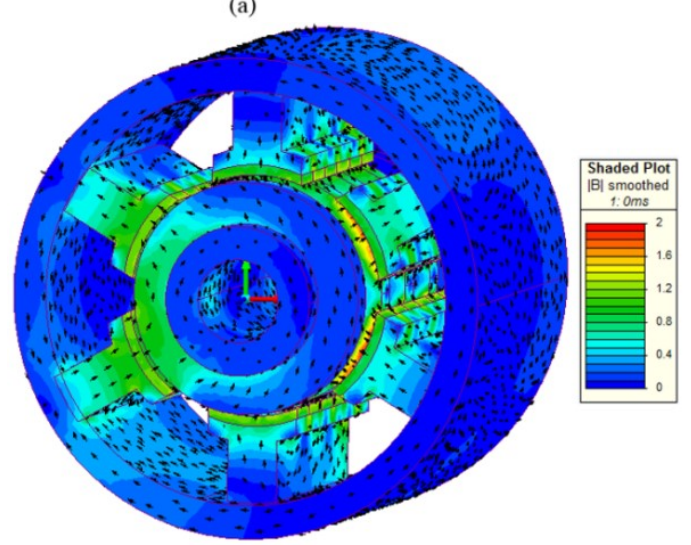

(b)

Fig. 10: (a) 3D mesh design (b) Magnetic flux density distribution 
The cogging force has been calculated using static simulation at discrete translator positions over an electrical cycle. Fig. 8 shows the harmonic analysis of the cogging results for a stator tooth shift of $0 \mathrm{~mm}$ to $4 \mathrm{~mm}$. With no shift $(0 \mathrm{~mm})$, the 6th harmonic is seen to be dominant. Equation (8) can be used to specifically target the 6th harmonic in a two stack machine by setting $k=6$ and $m=2$. The resulting $30^{\circ}$ shift corresponds to a physical shift of $2 \mathrm{~mm}$. Fig. 8 confirms the reduction in the 6th harmonic for a $2 \mathrm{~mm}$ shift and Fig. 9 shows the ripple profile. The displacement between stator poles under the same phase also reduces the fundamental magnetic flux harmonic, causing the average thrust force to be reduced. Table III presents the performance analysis of the machine in terms of cogging and average force for various pole shifts.

TABLE III

\begin{tabular}{c|c|c|c}
$\begin{array}{c}\text { COGGING AND AVERAGE FORCE VARIATION AT VARIOUS POLE SHIFTS } \\
\begin{array}{c}\text { Pole shift } \\
(\mathbf{m m})\end{array}\end{array}$ & $\begin{array}{c}\text { Cogging } \\
(\mathbf{N})\end{array}$ & $\begin{array}{c}\text { \% Cogging } \\
\text { reduction }\end{array}$ & $\begin{array}{c}\text { \% Force } \\
\text { reduction }\end{array}$ \\
\hline $\mathbf{0}$ & 24 & $0 \%$ & $0 \%$ \\
$\mathbf{1}$ & 19 & $20 \%$ & $2 \%$ \\
$\mathbf{2}$ & 6.5 & $73 \%$ & $3.5 \%$ \\
$\mathbf{3}$ & 13 & $46 \%$ & $9 \%$ \\
$\mathbf{4}$ & 16 & $33 \%$ & $12 \%$ \\
\hline
\end{tabular}

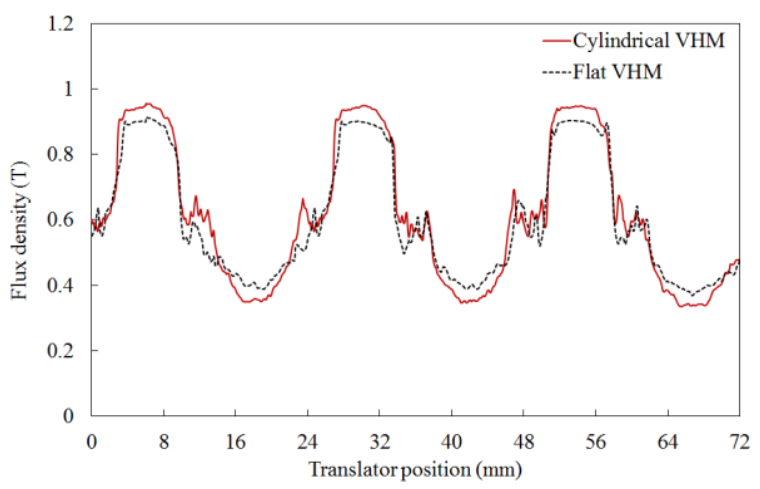

(a)

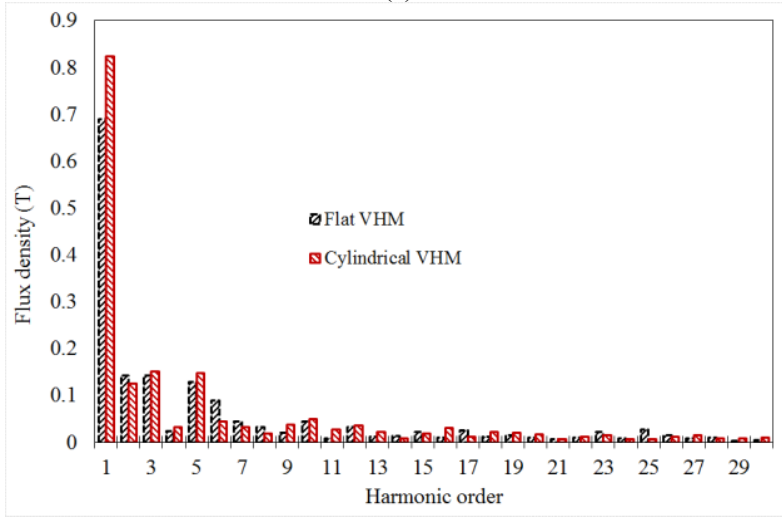

(b)

Fig. 11: (a) Air-gap flux density of flat and cylindrical model (b) harmonic analysis

\section{Electromagnetic Performance Comparison}

Both the stator and translator of the cylindrical machine have a 3D flux path and are assumed to be made of Soft Magnetic Composites (SMC), whereas the flat machine with its $2 \mathrm{D}$ path can be constructed from conventional iron laminations. Fig. 10 shows the 3D mesh of the FEA model and the no-load flux density distribution of the cylindrical VHM. Fig 11(a) represents the air-gap radial flux density of the flat and the cylindrical machines along the longitudinal direction. The cylindrical version has a higher air-gap flux density, due to the decreasing area as the flux travels radially towards the centre of the translator - a 'flux focusing' type effect. Consequently, Fig 11(b) shows that the force producing fundamental harmonic of the flux density is higher in the cylindrical version. Fig. 12(a) represents the three-phase no load back EMF waveform of the cylindrical and flat Vernier machines at a nominal speed of $1.2 \mathrm{~m} / \mathrm{s}$. Fig. 12(b) shows the cylindrical machine has a higher fundamental EMF harmonic, while both machines have a similar kind of higher order harmonic pattern due to the similar nature of the interaction of flux between stator PM and translator teeth.

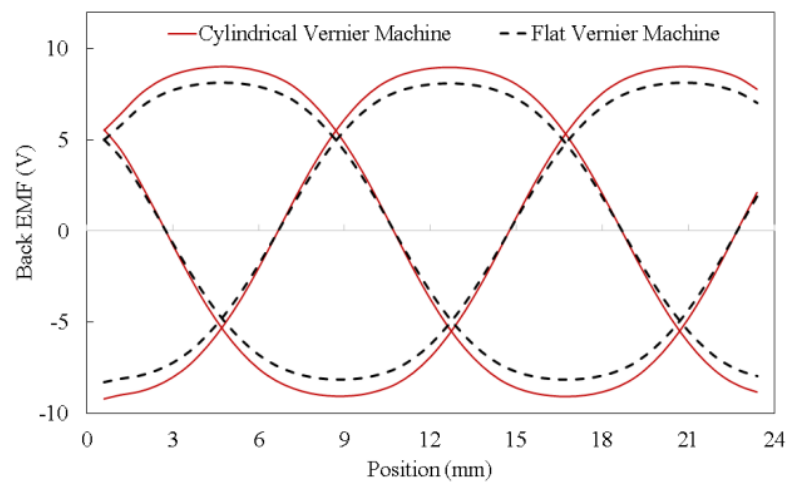

(a)

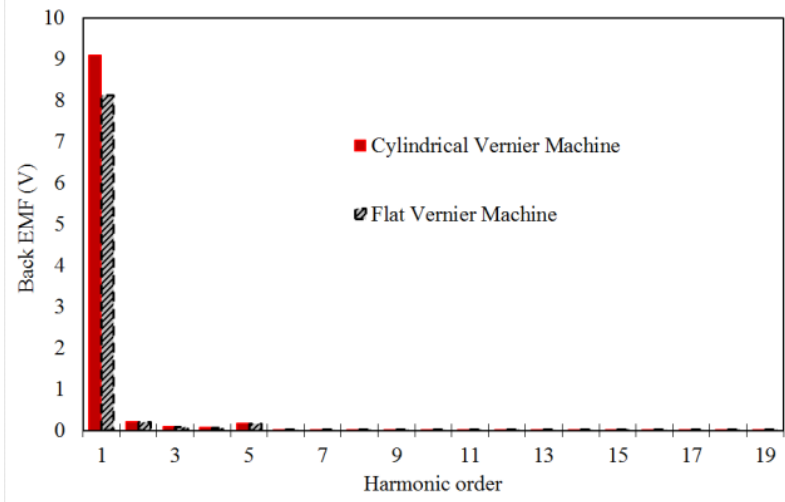

(b)

Fig. 12: (a) Predicted no load EMF comparison between flat and cylindrical model (b) harmonic analysis

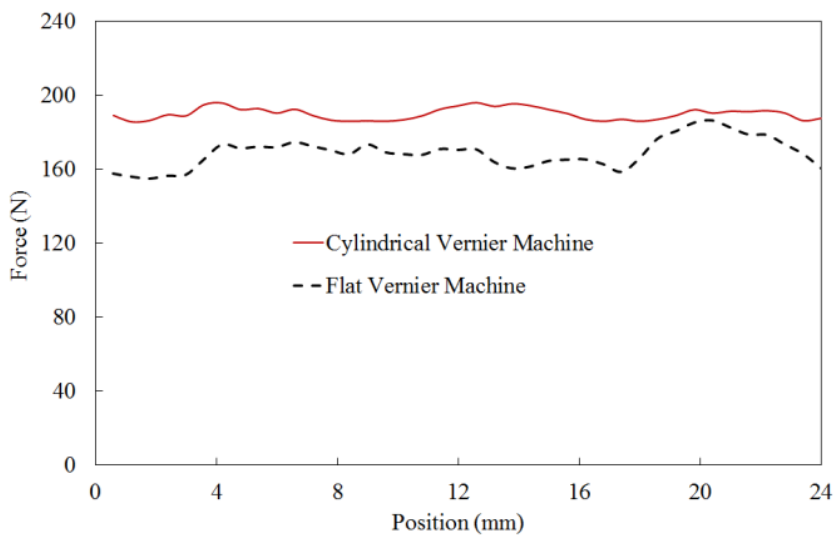

Fig. 13: Simulated thrust force comparison between flat and cylindrical VHM 
Fig. 13 shows the thrust force produced by both machines at the same rated MMF. A sinusoidal current was injected into the $\mathrm{q}$ axis of the machine as the PMs are surface mounted and have almost zero salient force. The average thrust force of the cylindrical model is found to be $190 \mathrm{~N}$ compared to $170 \mathrm{~N}$ for the flat model. This higher thrust force is due to the higher fundamental EMF component in the cylindrical model. The mechanical power $\left(P_{m}\right)$ is calculated in (9).

$$
P_{m}=F_{\text {avg }} \times v_{\text {rated }}
$$

Where $F_{\text {avg }}$ is the average thrust force and the $v_{\text {rated }}$ is the rated translator speed. Due to the low speed operation, the dominating loss in both machines is the copper loss. Eddy current loss in the PM is also taken into account and found to be higher in the cylindrical model due to the higher fringing flux in the air-gap. Table IV compares the predicted FEA performance between the unskewed flat version and the skewed cylindrical version of the machine.

TABLE IV

PERFORMANCE ANALYSIS FOR BOTH MACHINES

\begin{tabular}{c|c|c}
\hline Performance & $\begin{array}{c}\text { Cylindrical } \\
\text { (pole shifted) }\end{array}$ & Flat \\
\hline Open circuit voltage $(\mathrm{V})$ & 9 & 8.1 \\
No load flux linkage (Wb-turns) & 0.032 & 0.029 \\
Peak air-gap flux density (T) & 0.96 & 0.9 \\
Active air-gap area under stator pole $\left(\mathrm{mm}^{2}\right)$ & 9670 & 9720 \\
Average thrust force $(\mathrm{N})$ & 190 & 170 \\
\% Force ripple & 5 & 18 \\
Shear stress (kN/m $\left.{ }^{2}\right)$ & 12 & 13 \\
Force / PM mass $(\mathrm{N} / \mathrm{kg})$ & 1055 & 936 \\
Thrust force density $\left(\mathrm{kN} / \mathrm{m}^{3}\right)$ & 333 & 212 \\
Power density $\left(\mathrm{kW} / \mathrm{m}^{3}\right)$ & 400 & 255 \\
PM eddy current loss $(\mathrm{W})$ & 5.5 & 5.1 \\
Active Power $(\mathrm{W})$ & 228 & 202 \\
\hline
\end{tabular}

The flat machine can also be skewed in a similar manner as the cylindrical machine. Fig 14 shows the simulated cogging force for both skewed machines. The peaks are similar, although the flat version has a slightly higher peak to peak cogging force. Laboratory experience has shown that in terms of manufacture, skewing the cylindrical machine is easy to achieve as it consists of a single machined or pressed component, Fig. 15.

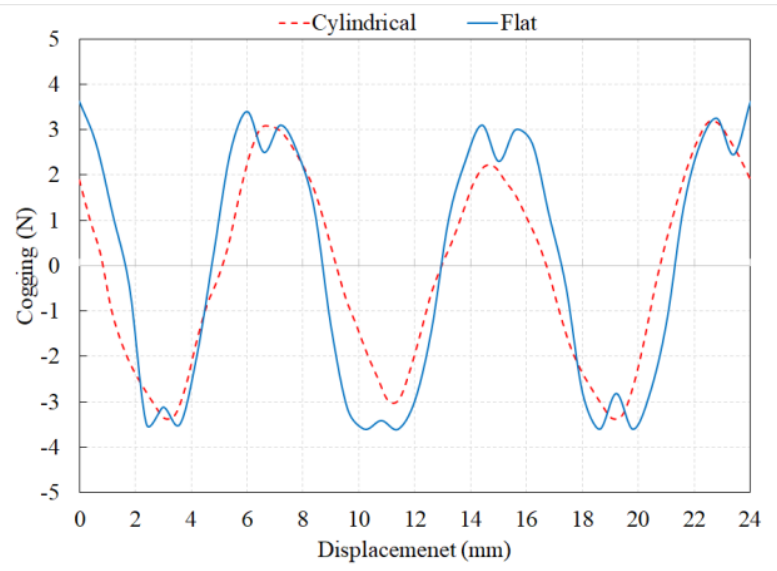

Fig. 14: Simulated cogging comparison between flat and cylindrical VHM

\section{PROTOTYPE MACHINE CONSTRUCTION \& ASSEMBLy}

A small scale laboratory prototype cylindrical machine has been designed and built to prove the concept and validate the FEA. Both the translator and the stator structure are made of soft magnetic composite (SMC) materials in order to accommodate the 3D flux path (radial, axial and circumferential). Component pressing is not practical for a one-off prototype and so the entire machine is made from 200 mm prototype SMC material blocks. The translator is made from a series of blocks mounted on a common shaft. The stator with six teeth is made from a stack of SMC blocks, shown in Fig. 15. Fig. 16 shows the fully assembled machine with six coils and the arc-shaped NdFeB magnets, which are glued to the surface of the stator teeth. Two $20 \mathrm{~mm}$ linear flanged ball bushings with a maximum dynamic load of $900 \mathrm{~N}$ each were mounted on the two translator support stands. The maximum length of each mechanical stroke is $200 \mathrm{~mm}$, which was restricted by the length of the translator. A linear ball screw actuator provides reciprocating motion and is used to test the prototype machine as a generator.
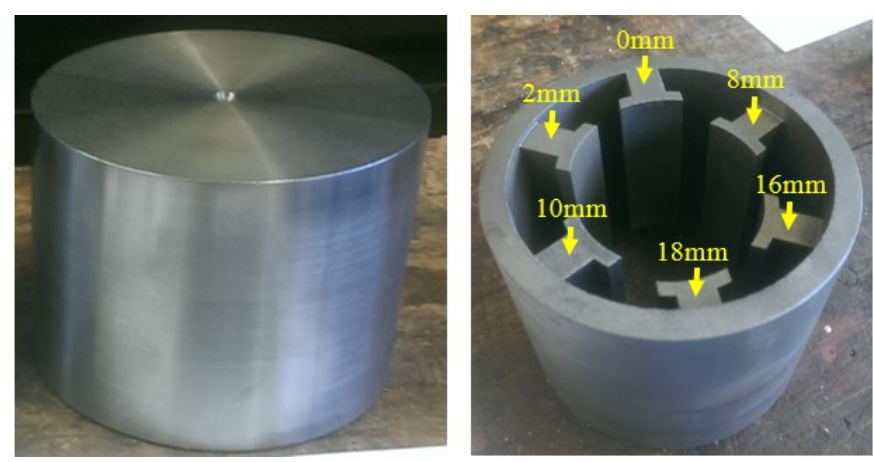

Fig. 15: Stack of cylindrical SMC blocks and machined stator. 


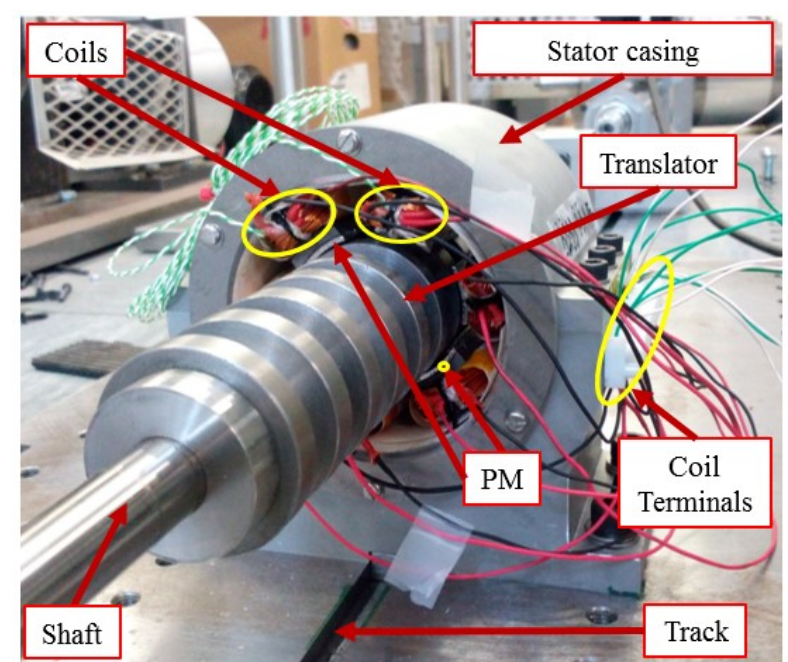

Fig. 16: Assembled stator on the bedplate and the full machine assembly.

Fig. 17 represents the experimental setup of the linear test rig which also includes a linear ball screw actuator, differential probes to measure currents and voltages, and a digital oscilloscopes to observe and record results.

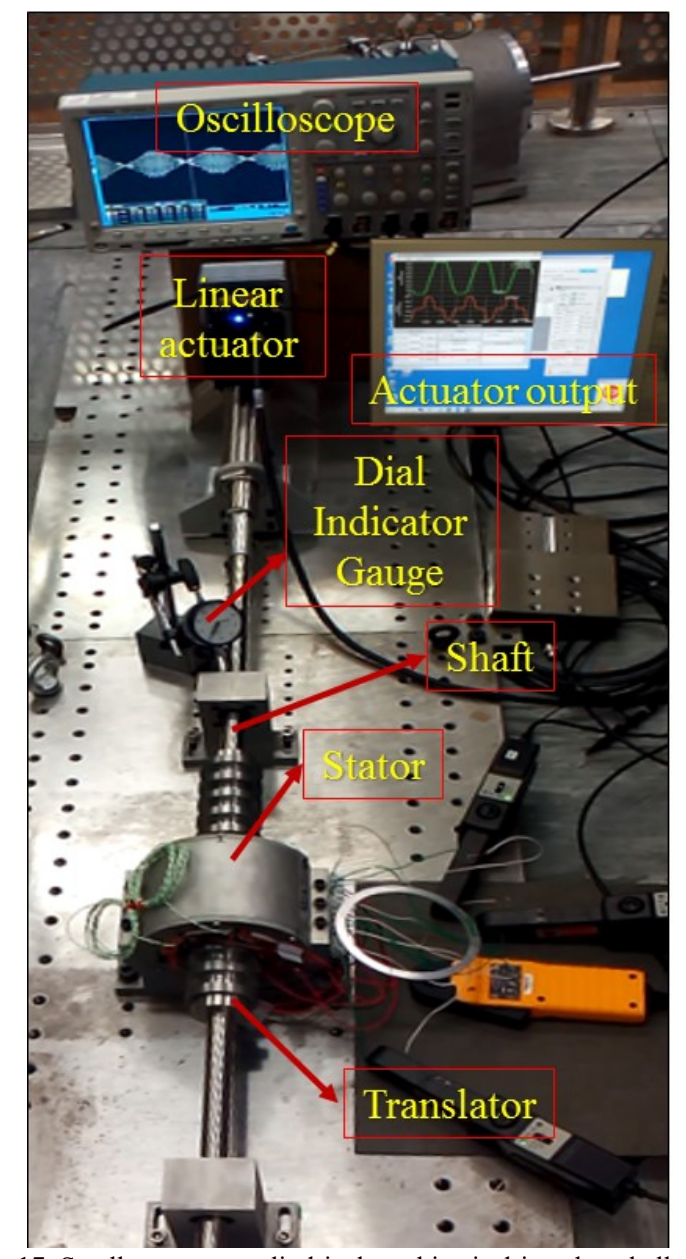

Fig. 17: Small prototype cylindrical machine is driven by a ball screw actuator and being tested at $0.3 \mathrm{~m} / \mathrm{s}$.

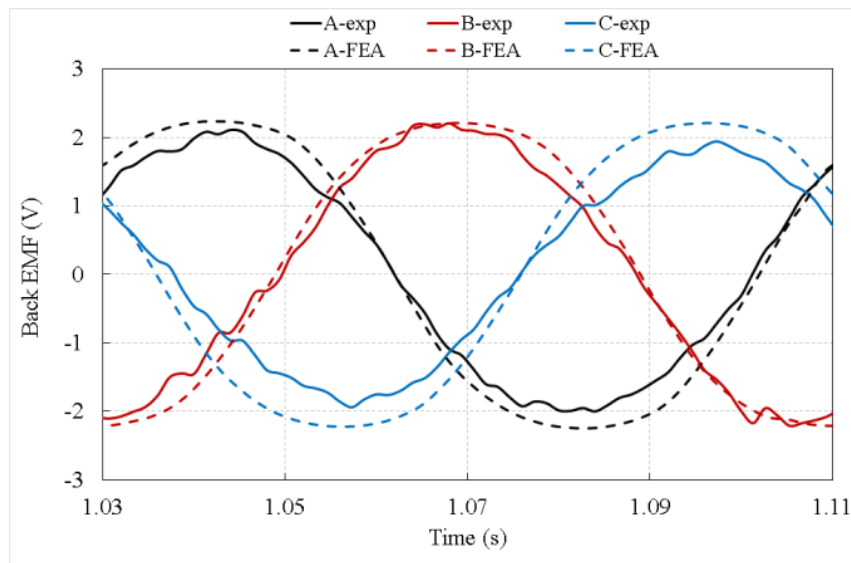

Fig. 18: Three phase no load back EMF comparison.

\section{PRototyPe MACHINE TESTING AND VALIDATION}

\section{A. Open Circuit Test at Constant Speed}

Fig. 18 presents the comparison between the simulation and experimental results of the no load back EMF over an electrical cycle at a constant speed of $0.3 \mathrm{~m} / \mathrm{s}$. In Fig. 19, it can be seen that the laboratory prototype has a non-uniform airgap. The FEA simulations were updated to reflect the error in concentricity, shown in Fig. 20.

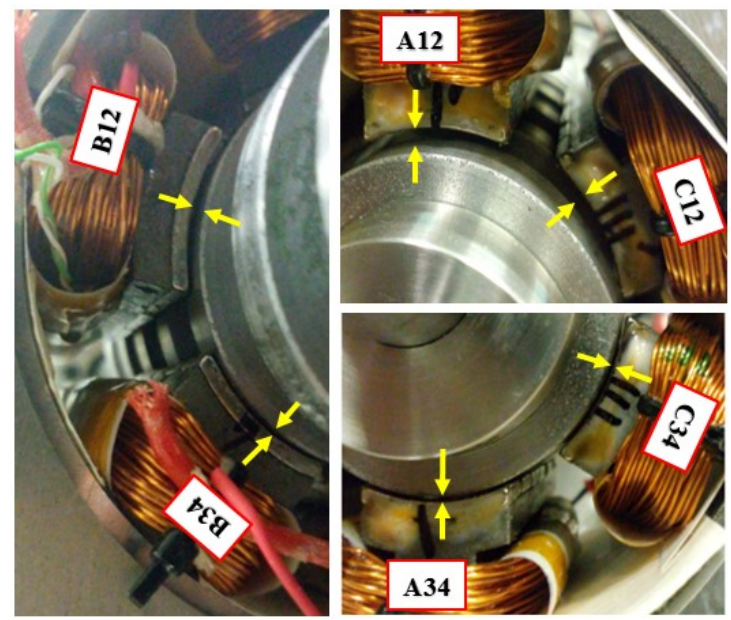

Fig. 19: Uneven mechanical air-gap regions of the prototype.

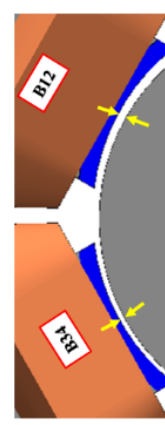

Fig. 20: Uneven mechanical air-gap regions (a) simulation (b) geometry.

\section{B. Non-uniform Air-gap}

The approximate air-gaps under each stator tooth were measured by brass filler gauges. To validate the prototype, an FEA model with approximate air-gaps was adapted to allow for a non-concentric translator. It was offset with respect to the 
$\mathrm{Y}$-axis (the centre line of phase-A) by $-0.4 \mathrm{~mm}$ and $-1 \mathrm{~mm}$ with respect to the $\mathrm{X}$-axis (perpendicular to the centre line of phase-A), giving a variation in the average air-gap across the three phases of $1 \mathrm{~mm}, 0.95 \mathrm{~mm}$, and $1.1 \mathrm{~mm}$. The average airgap was calculated by simply adding the air-gaps under two stator teeth in the same phase and dividing by 2 (i.e. (A12 + A34)/2). The offset in the air-gap is clearly visible in Fig. 19. Direct comparison and summary of the offset simulations and the experimental results are presented in Table $\mathrm{V}$.

The offset of the translator is likely not to be along the centre line of a tooth, and the simulation results presented in Table V are therefore not fully representative of the physical prototype as tested. It is also possible that the concentricity of the translator varies with position. Thus, although the offset simulation results give a close match to the measured phase EMF value, there is a maximum error of $4.8-5.7 \%$ in the peak value of simulated phase EMF results.

\section{Open Circuit Test at Varying Speed}

The machine is driven open circuit over a $200 \mathrm{~mm}$ displacement, with a peak speed of $1.4 \mathrm{~m} / \mathrm{s}$. Fig. 21 shows the no-load EMF results over two mechanical strokes under variable speed operation. The translator was reciprocating with an approximate sinusoidal displacement profile.

TABLE V

\begin{tabular}{|c|c|c|c|c|c|c|}
\hline \multirow[b]{2}{*}{$\begin{array}{l}\text { Stator } \\
\text { tooth }\end{array}$} & \multicolumn{2}{|c|}{ FEA } & \multicolumn{2}{|c|}{ Modified FEA } & \multirow{2}{*}{$\begin{array}{c}\text { Exp. } \\
\text { back } \\
\text { EM } \\
\text { F } \\
\text { (V) }\end{array}$} & \multirow{2}{*}{$\begin{array}{c}\% \\
\text { Erro } \\
\mathrm{r} \text { in } \\
\text { back } \\
\text { EM } \\
\mathrm{F}\end{array}$} \\
\hline & $\begin{array}{l}\text { Air- } \\
\text { gap } \\
(\mathrm{mm})\end{array}$ & $\begin{array}{c}\text { Back } \\
\text { EMF } \\
(V)\end{array}$ & $\begin{array}{c}\text { Approx. } \\
\text { Air-gap } \\
(\mathrm{mm})\end{array}$ & $\begin{array}{c}\text { FEA } \\
\text { back } \\
\text { EMF } \\
(\mathrm{V})\end{array}$ & & \\
\hline Coil-A12 & 1 & 1.2 & 1.6 & 0.8 & 0.75 & 6.7 \\
\hline Coil-A34 & 1 & 1.17 & 0.4 & 1.55 & 1.46 & 6.2 \\
\hline Phase-A & 1 & 2.2 & 1.0 & 2.2 & 2.1 & 4.8 \\
\hline Coil-B12 & 1 & 1.17 & 1.2 & 1.07 & 1 & 7.0 \\
\hline Coil-B34 & 1 & 1.2 & 0.7 & 1.38 & 1.29 & 7.0 \\
\hline Phase-B & 1 & 2.2 & 0.95 & 2.3 & 2.19 & 5.0 \\
\hline Coil-C12 & 1 & 1.17 & 1.4 & 0.96 & 0.89 & 7.9 \\
\hline Coil-C34 & 1 & 1.2 & 0.8 & 1.28 & 1.2 & 6.7 \\
\hline Phase-C & 1 & 2.2 & 1.1 & 2.05 & 1.94 & 5.7 \\
\hline
\end{tabular}

\section{Static Tests}

\section{1) Cogging Force}

An open circuit static test was performed to measure the cogging force in the prototype machine. The translator was moved by one electrical cycle $(24 \mathrm{~mm})$ in steps of $1 \mathrm{~mm}$. Fig. 22 shows the measured and simulated cogging force, where the simulation was performed using the non-uniform air-gap described above. During the experiment, the net measured force is always positive and there is a positive offset in the experimental result of cogging. This is due to high friction in the linear bearings opposing the translator movement. If the experiment is repeated in the opposite direction, the offset is reversed. The offset can be removed from the results to eliminate the bearing affect. The resulting measured cogging force correlates well with the FEA result with a maximum variation of around $10 \%$. This deviation, which is slightly larger than the error in EMF prediction, is thought to be partly due to the tolerance of the load cell (rated at $2.5 \mathrm{kN}$ ) and imbalance in the mechanical air-gap.

\section{2) Thrust Force}

Static force measurement was performed at the peak force position for different DC currents. $0 \mathrm{~A}$ to $10 \mathrm{~A} \mathrm{DC}$ was applied to phase-A with a step of $2 \mathrm{~A}$. Phases $\mathrm{B}$ and $\mathrm{C}$ were supplied by the negative half value of the Phase $A$ (i.e. $\mathrm{I}_{\mathrm{A}}=\mathrm{I}_{\mathrm{dc}}, \mathrm{I}_{\mathrm{B}}=\mathrm{I}_{\mathrm{C}}=-$ $I_{d c} / 2$ ). Fig. 23 demonstrates the peak force comparison between FEA and experimental results, which has a similar error to the cogging measurement at less than $10 \%$.

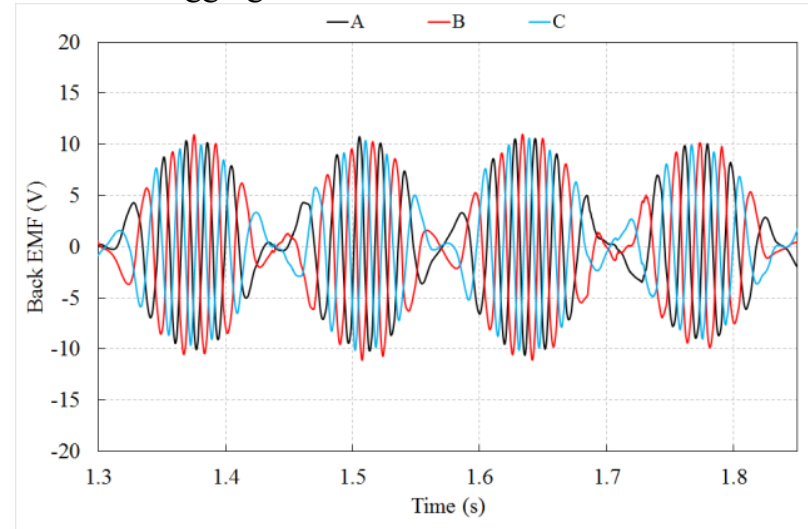

Fig. 21: Measured three phase no load back EMF for two mechanical strokes under linear reciprocating motion.

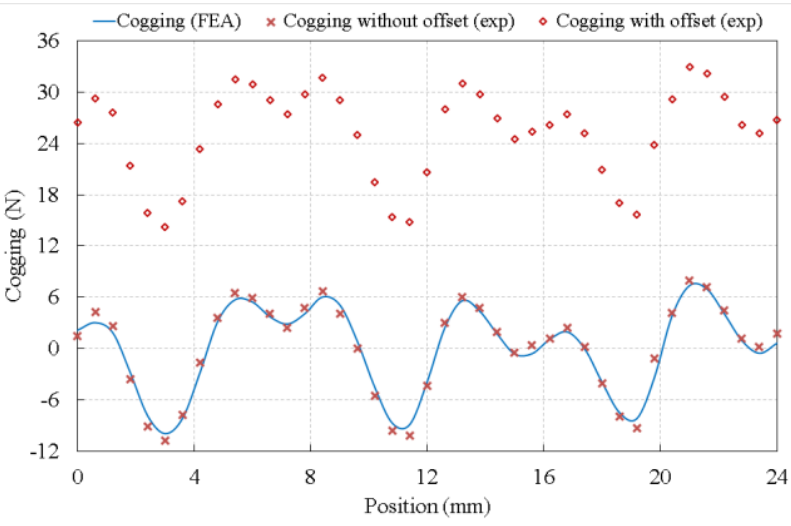

Fig. 22: Cogging force comparison between experimental and predicted results for the cylindrical machine. 


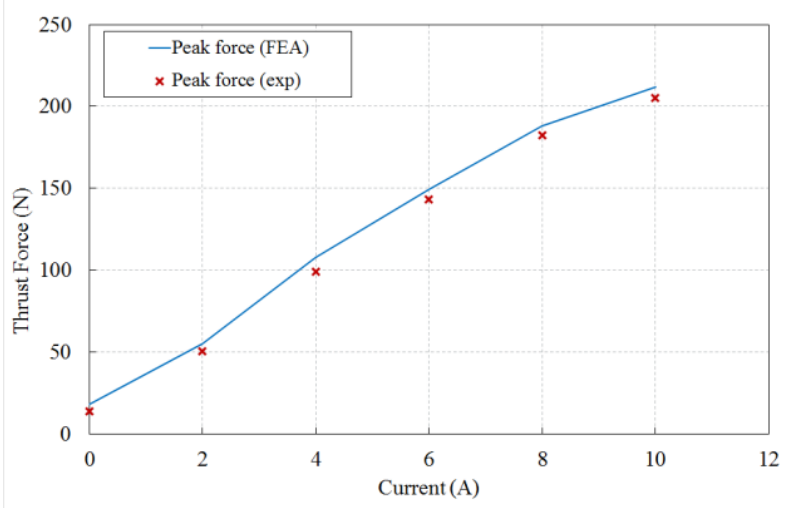

Fig. 23: Thrust force comparison between experimental and predicted results for varying current.

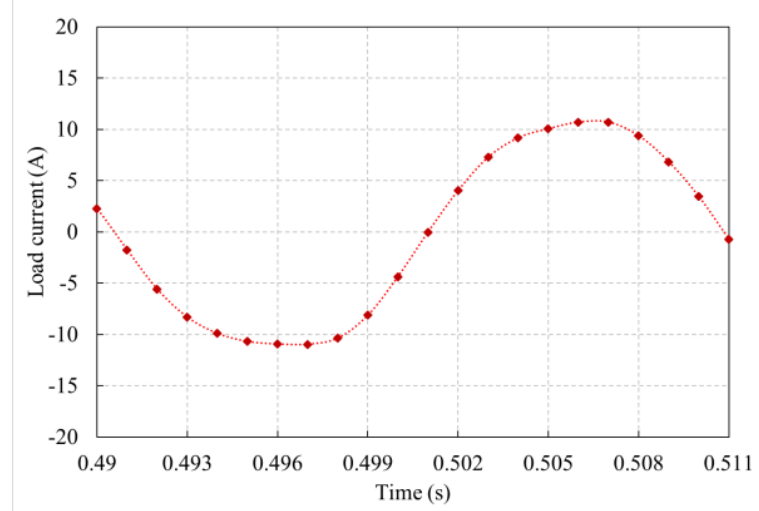

Fig. 24: Load current at $0.5 \mathrm{Ohm}$ resistive load

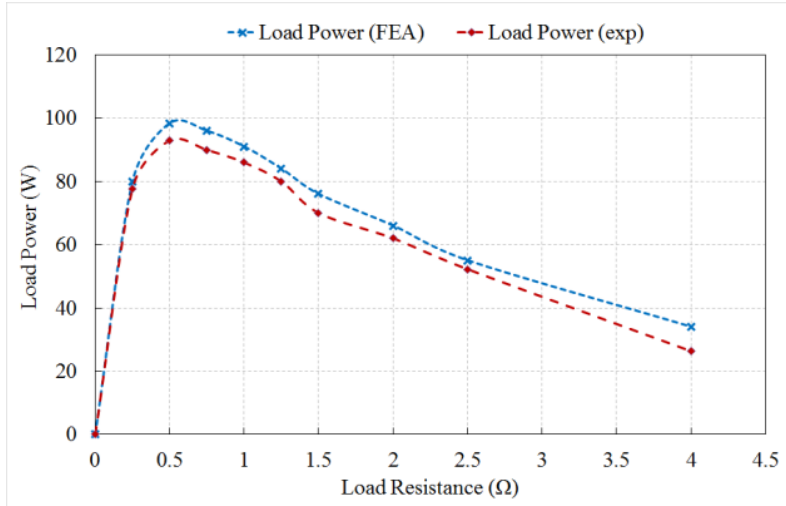

Fig. 25: Load power (rms) comparison at various resistive loads

\section{3) Load Testing}

This machine was primarily designed to operate as a generator connected to a fully rated rectifier. However, for the purpose of laboratory validation, a simple star connected three phase resistive load was used to validate performance under load. Load power is calculated using measured voltage and current results. Fig. 24 shows the transient load current for an electrical cycle at a speed of $1.4 \mathrm{~m} / \mathrm{s}$ at $0.5 \Omega$ load. Fig. 25 demonstrates the power output verses load resistance graph of the machine. It is found that for both measured and predicted results, maximum power transfer occurred at around $0.5 \Omega$. The maximum measured power was $92.5 \mathrm{~W}$ rms compared to a predicted value of $98.5 \mathrm{~W}$ rms. The error on the power predictions is therefore $6.5 \%$.

The error on the EMF prediction per phase was shown in
Table V to be between 4.8 and $5.7 \%$ on the peak value. If the emf was a pure Sine wave, this would correspond to a $3.4-$ $4.0 \%$ error in the rms value. As power is related to the square of the voltage, a $6.6-7.9 \%$ error on the power would be expected. The simulation error on the loaded results is therefore consistent with the error in the emf discussed above.

\section{CONCLUSION}

A new linear cylindrical version of the Vernier Hybrid Machine has been designed and developed. Basic mechanical design development and FEA have been performed to show that at this radius, the cylindrical machine appears to offer a $10 \%$ higher force compared to the double-sided flat topology with the same magnet mass and current density. A pole shifting method has been utilised to reduce the cogging and the force ripple of the machine down to $6 \%$ of the rated force by the elimination of the sixth harmonic. The build, assembly and testing of a prototype have been presented to validate the concept of the cylindrical topology in the laboratory.

\section{REFERENCES}

[1] H. Polinder, B. C. Mecrow, A. G. Jack, P. G. Dickinson, and M. A Mueller, "Conventional and TFPM linear generators for direct-drive wave energy conversion," IEEE Transactions on Energy Conversion, vol. 20, pp. 260-267, 2005.

[2] H. Polinder, B. C. Mecrow, A. G. Jack, P. Dickinson, and M. A. Mueller, "Linear generators for direct-drive wave energy conversion," in IEEE International Electric Machines and Drives Conference, 2003. IEMDC'03. 2003, pp. 798-804

[3] L. Huang, H. Yu, M. Hu, J. Zhao, and Z. Cheng, "A novel fluxswitching permanent-magnet linear generator for wave energy extraction application," in IEEE Transactions on Magnetics, vol. 47, pp. 1034-1037, 2011.

[4] M. A. Mueller and N. J. Baker, "Modelling the performance of the vernier hybrid machine," IEEE Proceedings-Electric Power Applications, vol. 150, pp. 647-654, 2003.

[5] H. Weh, "Design of integrated propulsion, guidance, and levitation system by magnetically excited transverse flux linear motor (TFMLM)," IEEE Trans. Energy Convers., vol. 19, pp. 477-484, 2004.

[6] J. Wang and N. J. Baker, "Comparison of flux switching and modulated pole linear machines for use with a free piston," in IEEE International Electric Machines \& Drives Conference (IEMDC), 2015, pp. 642-648.

[7] D. Li, R. Qu, J. Li, and W. Xu, "Consequent-pole toroidal-winding outer-rotor vernier permanent-magnet machines," IEEE Trans. Ind. Appl., vol. 51, no. 6, pp. 4470-4481, 2015.

[8] N. Baloch, S. Khaliq, and B.-I. Kwon, "HTS dual-stator spoke-type linear vernier machine for leakage flux reduction," IEEE Trans. On Magn., vol. 53, no. 11, pp. 1-4, 2017.

[9] E. Spooner and L. Haydock, "Vernier hybrid machines," in IEE Proceedings - Electric Power Applications, vol. 150, no. 6, pp. $655-$ 662, 7 Nov. 2003.

[10] S.-U. Chung, Y.-D. Chun, B.-C. Woo, D.-K. Hong, and J.-Y. Lee, "Design considerations and validation of permanent magnet vernier machine with consequent pole rotor for low speed servo applications," Journal of Electrical Engineering and Technology, vol. 8, no. 5, pp. 1146-1151, 2013.

[11] D. Li, R. Qu, and T. A. Lipo, "High-power-factor vernier permanentmagnet machines," IEEE Trans. Ind. Appl., vol. 50, no. 6, pp. 3664 $3674,2014$.

[12] I. Boldea, Jichun Zhang and S. A. Nasar, "Theoretical characterization of flux reversal machine in low-speed servo drives-the pole-PM configuration," in IEEE Trans. Ind. Appl, vol. 38, no. 6, pp. 1549-1557, Nov.-Dec. 2002

[13] Boldea, I. and Nasar, S.A., 1997. Linear motion electromagnetic devices. Taylor \& Francis. 
[14] A. W. van Zyl, C. G. Jeans, R. J. Cruise, and C. F. Landy, "Comparison of force to weight ratios between a single-sided linear synchronous motor and a tubular linear synchronous motor," in International Conference on Electric Machines and Drives, 1999, pp. 571-573.

[15] H. Jing, N. Maki, T. Ida,and M. Izumi, "Electrical design of large-scale tubular PM linear generators for wave energy conversion," IEEJ Transactions on Electrical and Electronic Engineering, Dec 2017, 12, pp.S113-S119.

[16] M. A. H. Raihan, N. J. Baker, K. J. Smith and A. A. Almoraya, "Development and Testing of a Novel Cylindrical Permanent Magnet Linear Generator," 2018 XIII International Conference on Electrical Machines (ICEM), Alexandroupoli, 2018, pp. 2137-2143.

[17] N. J. Baker, M. A. H. Raihan and A. Almoraya, "A Cylindrical Linear Permanent Magnet Vernier Hybrid Machine for Wave Energy," in IEEE Trans. Energy Convers., 2018.

[18] M. A. H. Raihan, N. J. Baker, K. J. Smith, and A. A. Almoraya, "An Ecore linear vernier hybrid permanent magnet machine with a segmented translator for direct drive wave energy converter," in International Electric Machines and Drives Conference (IEMDC), 2017, pp. 1-6.

[19] Baker, N.J., Mueller, M.A. and Raihan, M.A.H., 2016, September. "All electric drive train for wave energy power take off". In 5th IET International Conference on Renewable Power Generation (RPG) 2016, (pp. 1-6). IET.

[20] K. Atallah and D. Howe, "A novel high-performance magnetic gear," in IEEE Trans. On Magn, vol. 37, no. 4, pp. 2844-2846, July 2001

[21] N. Iwabuchi, A. Kawahara, T. Kume, T. Kabashima, and N. Nagasaka, "A novel high-torque reluctance motor with rare-earth magnet," in IEEE Trans. Ind. Appl., vol. 30, pp. 609-614, 1994.

[22] N.W. Frank and H.A. Toliyat, "Gearing ratios of a magnetic gear for wind turbines,"inIEEE International Electric Machines and Drives Conference(IEMDC),May 2009, pp. 1224-1230.

[23] Z. Zhu and D. Howe, "Influence of design parameters on cogging torque in permanent magnet machines," IEEE Transactions on Energy convers., vol. 15 , no. 4, pp. 407-412, Dec 2000

[24] Jungmayr, G., Loeffler, J., Winter, B., Jeske, F. and Amrhein, W., "Magnetic gear: Radial force, cogging torque, skewing, and optimization.” IEEE Trans. Ind. Appl, 52(5), pp.3822-3830, 2016.

[25] Lei Huang, Minqiang Hu1, Jing Liu2, Chunyuan Liu, Weibo Zhong, "Design and Analysis of a Linear Hybrid Excitation Flux-Switching Generator for Direct Drive Wave Energy Converters" Advances in
Mechanical Engineering (Hindawi Publishing Corporati;2013, p1, Academic Journal article, January 2013

\section{BIOGRAPHIES}

Mohammad A.H. Raihan received his B.Sc. degree in electrical engineering from the Military Institute of Science \& Technology (MIST), Dhaka, Bangladesh in 2013, and his M.Sc. degree in electrical Power Engineering from Newcastle University, Newcastle upon Tyne, U.K., in 2015. $\mathrm{He}$ is currently working towards his $\mathrm{PhD}$ at Newcastle University, Newcastle upon Tyne, U.K. His research interests and experience include different rotary and linear electrical machine design for automotive applications and renewable energy generation.

Nick J. Baker received a MEng Degree in Mechanical Engineering from Birmingham University, UK, in 1999 and a Ph.D. from Durham University U.K in 2003 for work in electrical machine design for marine renewable energy devices. He is presently a Senior Lecturer at Newcastle University's Electrical Power Group. Nick is a machine designer with research projects across the automotive, aerospace and renewable energy sector.

Kristopher J. Smith completed an apprenticeship with British Telecom before attended Northumbria University. Here he received a BSc(Hons) in Communications \& Electronic Engineering and a MSc in Microelectronic Engineering. In 2006 he joined Newcastle University to complete an Engineering Doctorate (EngD) with sponsorship from Dyson. His research focused on Power Supply Quality in Brushless Drives. After completing the doctorate Kris has moved into a Teaching Fellowship at Newcastle University. His research interests are mainly in permanent magnet machine design.

Ahmed A. Almoraya received his BSc degree in Electrical Engineering from Riyadh College of Technology, Saudi Arabia in 2009, and his MSc degree in Electrical Power from Newcastle University, Newcastle upon Tyne, UK in 2013. He is currently working towards his PhD degree in Newcastle University, Newcastle upon Tyne, UK. His research interests include electrical machines design. His employment experience included the ministry of water and Technical and Vocational Training Corporation, Saudi Arabia. 